\title{
Thoracoscopy-assisted first rib resection for the treatment of thoracic outlet syndrome caused by fibrous dysplasia: A report of two cases
}

\author{
AIERKEN REHEMUTULA ${ }^{1}, \mathrm{LI} \mathrm{ZHANG}^{1}, \mathrm{CONG} \mathrm{YU}^{1}, \mathrm{LIN} \mathrm{CHEN}^{1}$ and YUDONG GU ${ }^{1,2}$ \\ ${ }^{1}$ Department of Hand Surgery, Huashan Hospital, Fudan University; \\ ${ }^{2}$ Shanghai Key Laboratory of Peripheral Nerve and Microsurgery, Shanghai 200040, P.R. China
}

Received July 21, 2014; Accepted January 16, 2015

DOI: $10.3892 /$ etm.2015.2371

\begin{abstract}
This study reports two rare cases of thoracic outlet syndrome (TOS) caused by fibrous dysplasia of the first rib. Two patients, aged 19 and 29 years old, were admitted with TOS in the lower trunk of the brachial plexus caused by an inflated first rib. In these two cases symptoms included hypoesthesia of the anterior medial aspect of the forearm and two fingers in the ulnar side, and progressive weakness of the upper limbs. Surgery was required to resect the first rib. Transaxillary and supraclavicular excisions were challenging to perform due to the involvement of the subclavian vasculature and brachial plexus. Thoracoscopy was used in these cases in order to peel the pleura off the first rib and facilitate resection by the supraclavicular approach. None of the patients exhibited nerve or vascular complications following the surgery.
\end{abstract}

\section{Introduction}

Thoracic outlet syndrome (TOS) is a syndrome caused by compression of the subclavian vein or artery or the brachial plexus branches that cross the thoracic outlet. The neurovascular bundle passes through the narrow confines of the interscalene triangle as well as the costoclavicular triangle and the subcoracoid space on its way from the neck through the axilla and into the upper arm (1). In $85-97 \%$ of TOS cases, compression occurs in the brachial plexus $(2,3)$ where it affects one or more of the nerves that innervate the upper limb and/or blood vessels as they pass between the chest and upper extremity. This includes the brachial plexus, the subclavian artery and, rarely, the subclavian vein, which does not normally pass through the scalene hiatus.

Correspondence to: Professor Lin Chen, Department of Hand Surgery, Huashan Hospital, Fudan University, 12 Middle Wulumuqi Road, Shanghai 200040, P.R. China

E-mail: peng-f@163.com

Key words: fibrous dysplasia, first rib, resection, thoracic outlet syndrome, thoracoscopy
Fibrous dysplasia (FD) is a developmental skeletal anomaly in which osteoblasts do not undergo normal morphological differentiation and maturation, leading to the replacement of normal marrow and cancellous bone by immature bone and fibrous stroma (4,5). Between 6 and $20 \%$ of monostotic FD occurs in the ribs, with the second rib being most commonly affected (6). Approximately $55 \%$ of patients with polyostotic FD have rib involvement (7), usually in the lateral or posterior aspect of the rib. FD is typically asymptomatic unless the lesion is large enough to cause local pressure symptoms and/or pathological fractures $(6,8)$. FD and other tumors of the first rib are rare and those causing TOS are even more so.

\section{Case reports}

Informed consent. Written informed consent was obtained from all of the patients.

Case 1. A 19-year-old male presented with a history of hypoesthesia on the ulnar side of his right hand over three months, at the Department of Hand Surgery, Huashan Hospital (Shanghai, China). On physical examination, intrinsic muscular atrophy on the right hand was noted along with hypoesthesia on the ulnar side of the right forearm, hand, ring finger and little finger. The muscle strength of adduction and abduction in the second to fourth fingers was reduced, and thumb opposition function was restricted. The Wright, Adson's and costoclavicular crushing provocation tests were positive. In an imaging and nerve study a neck X-ray showed a lesion in the first rib (Fig. 1), computed tomography (CT) showed benign bone tumors or tumor-like lesions in the first rib (Fig. 2), and a bone scan showed an abnormal uptake of radioactivity in the first and second right ribs (Fig. 3). Magnetic resonance (MR) imaging of the neck showed abnormal signals in the right first rib and evidence of bone-borne disease. Laboratory results were unremarkable. The diagnosis was TOS of the lower trunk, occupying the first rib on the right side.

Case 2. A 29-year-old male visited the Department of Hand Surgery, Huashan Hospital with a history of hypoesthesia and progressive weakness of the left upper limb over six 


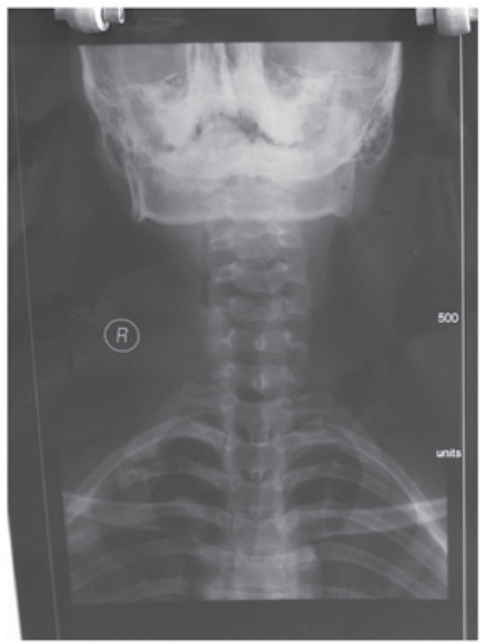

Figure 1. Neck X-ray of case 1 showing a lesion in right first rib.

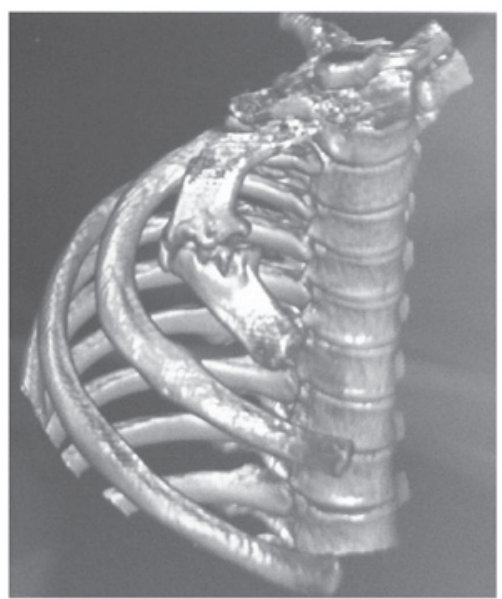

Figure 2. Three-dimensional computed tomography reconstruction of the thorax of case 1 showing benign bone tumors or tumor-like lesions in the right first rib.

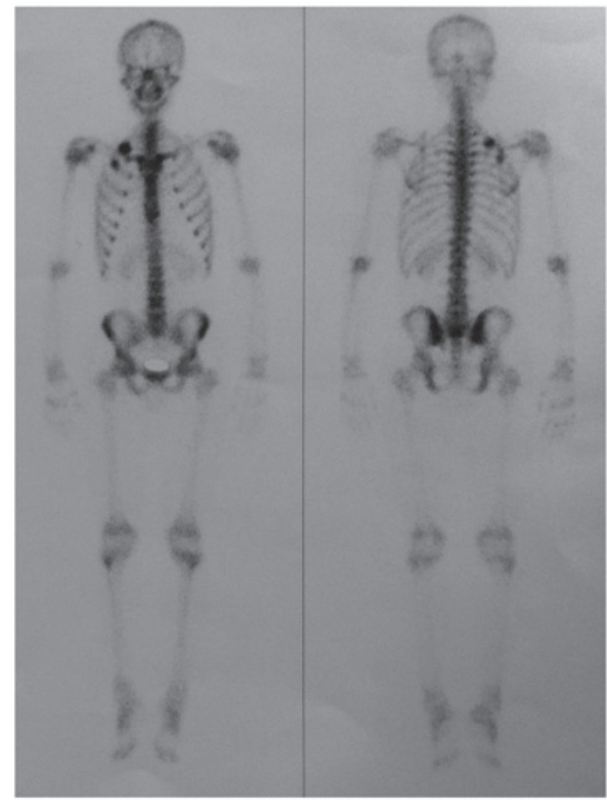

Figure 3. Emission computerized tomography bone scan of case 1 showing an abnormal uptake of radioactivity in the first and second right rib.

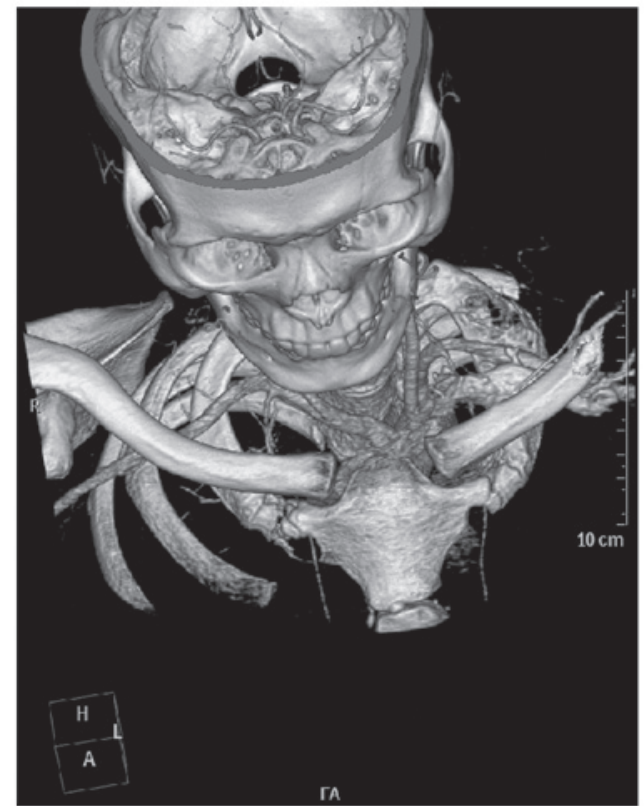

Figure 4. Three-dimensional computed tomography reconstruction of the neck and thorax of case 2 showing left first rib expansion.

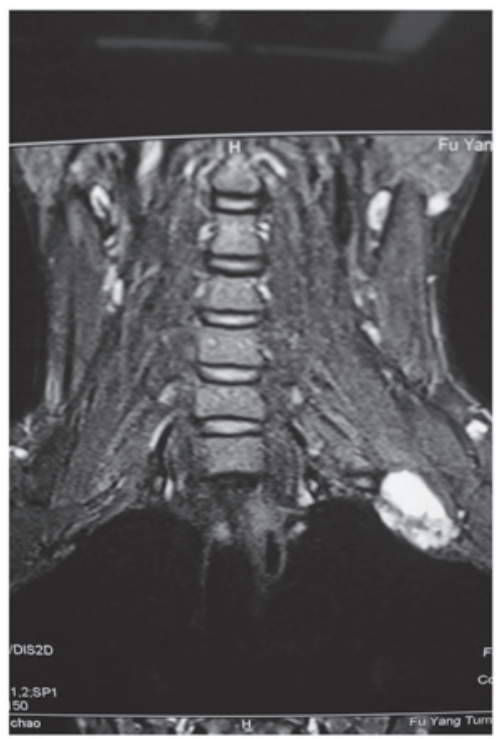

Figure 5. Magnetic resonance imaging of the neck of case 2 is abnormal with an increased signal on the left in the first rib and bone-borne disease.

months. Physical examination revealed no atrophy of the intrinsic muscles of the hand but the flexion strength of the wrist and finger was decreased. Thumb opposition function was normal. The Wright and Adson's provocation tests were positive, while the costoclavicular crushing test was negative. A neuroimaging study with three-dimensional (3D) CT reconstruction showed first rib expansion (Fig. 4). Neck MR results were abnormal with a decreased signal on the right in the first rib, and evidence of bone-borne disease (Fig. 5). Electromyography showed reduced nerve conduction velocity in the medial cutaneous nerve of the forearm. A chest X-ray showed a lesion in the first rib (Fig. 6) and laboratory results were unremarkable. A diagnosis of TOS in the lower trunk with a mass in the first rib on the left side was made. 
Table I. Thoracic outlet syndrome cases caused by first rib lesion and the resection approaches taken.

\begin{tabular}{|c|c|c|}
\hline First author, year (ref) ${ }^{a}$ & Type & Resection \\
\hline Devin, 1981 (13) & Neurogenic & Subclavicular approach with a medial clavicular resection \\
\hline Karanjia, 1990 (14) & Neurogenic and venous & Transaxillary excision \\
\hline Melliere, 1991 (9) & Neurogenic and arterial & Supraclavicular excision of the medial clavicle and first rib \\
\hline de Montpréville, 1995 (15) & Subclavian vessels & Transcervical-thoracic approach with resection of the medial clavicle \\
\hline Kemp, 2012 (16) & Neurogenic & Thoracotomy \\
\hline
\end{tabular}

${ }^{\mathrm{a} E a c h}$ reference describes a single case.

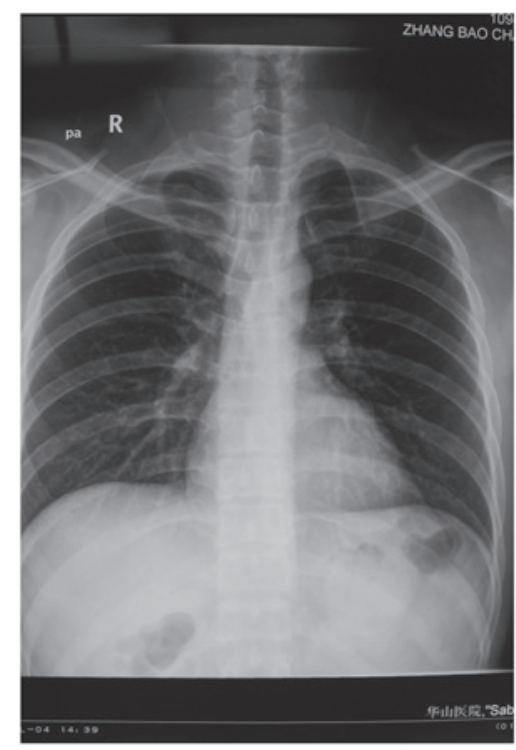

Figure 6. Chest X-ray of the chest of case 2 showing a lesion in the left first rib.

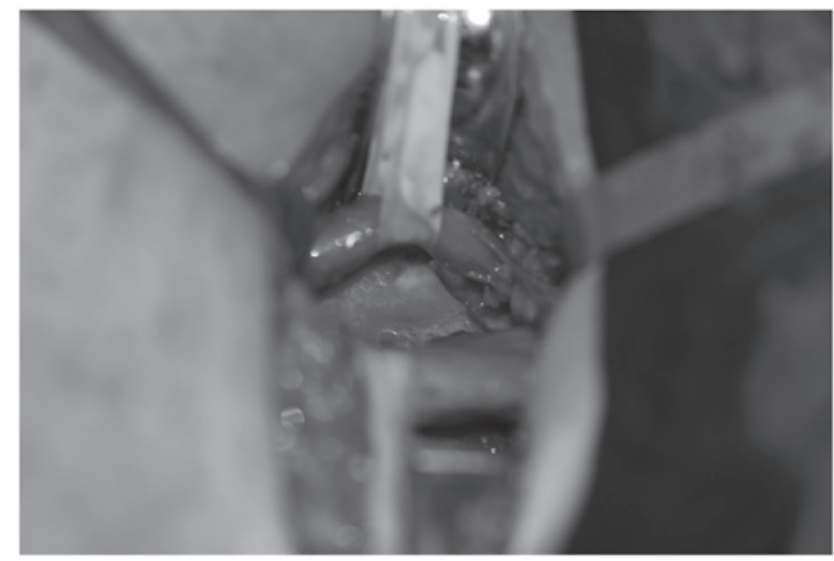

Figure 7. Subclavian vasculature and brachial plexus were exposed and released carefully using the supraclavicular route.

Surgical procedure. Once a diagnosis has been made, surgery should be contemplated only if conservative management has failed. In the present two cases, it was clear that TOS was caused by a tumor in the first rib and that the lesion required resection. There are two popular procedures for first rib resection: A transaxillary and a supraclavicular approach. In the

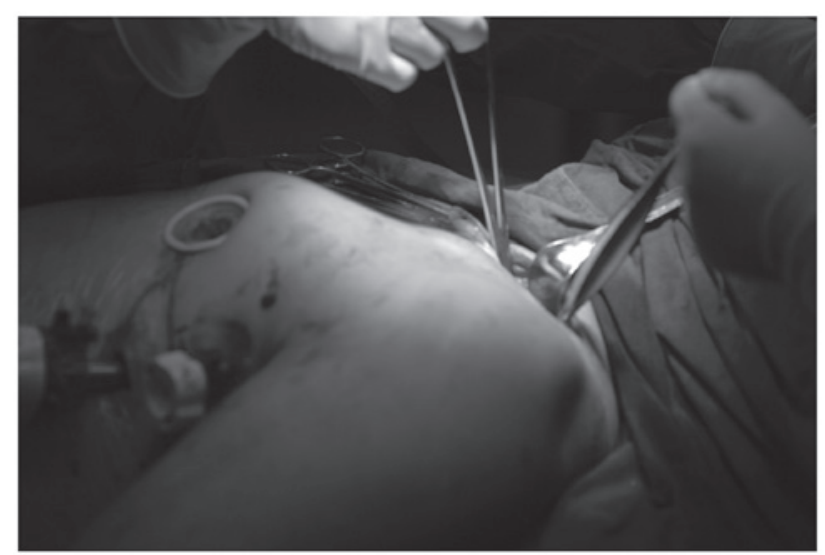

Figure 8 . Three ports of entry are made for thoracoscopy access.

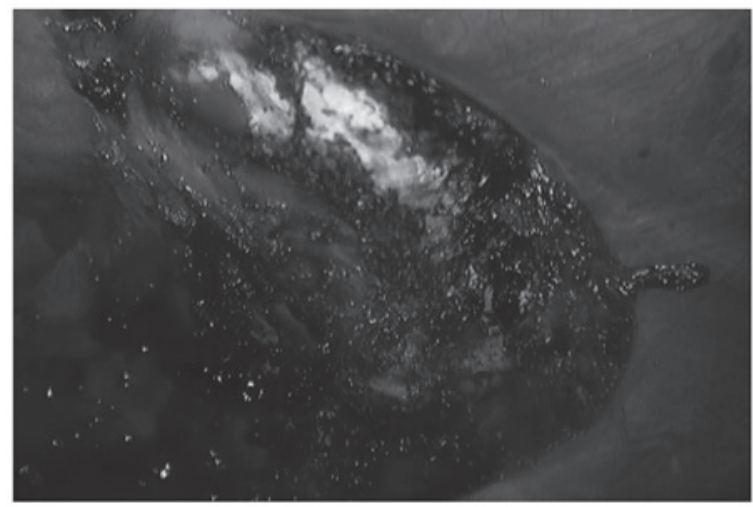

Figure 9. Lower edge of the first rib is stripped in the thoracoscopy.

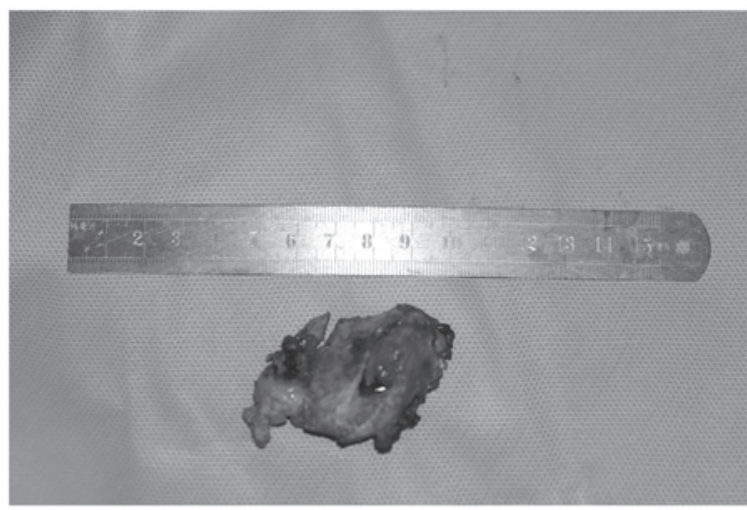

Figure 10. First rib is resected easily by the supraclavicular route. 
current cases a new thoracoscopy-assisted supraclavicular approach was used. For the extirpation of the first rib the patient took a supine position. Using the supraclavicular route, the subclavian vasculature and brachial plexus were decompressed and released carefully (Fig. 7). The upper edge of the first rib was stripped, the thoracoscope was placed on the body of the patient and three ports of entry were made for thoracoscopy access (Fig. 8). The lower edge of the first rib was then stripped (Fig. 9) and the rib was resected in a straightforward manner using the supraclavicular route (Fig. 10). Final pathology confirmed FD after two weeks, and the patients did not have any complications. After a week, when the patients left the hospital, the symptoms of numbness, hypoesthesia and the feeling of weakness had improved.

\section{Discussion}

TOS caused by a tumor in the first rib is rare and, to the best of our knowledge, has been reported only 12 times in the English-language literature over the past one and a half centuries, with the majority of cases due to osteochondroma (9). A variety of surgical approaches have been used, including the intercapulovertebral route for posterior tumors and thoracotomy, supraclavicular, and transaxillary approaches for anterior tumors. The first reported excision of a cervical rib was performed by Coote at St. Bartholomew's Hospital (London, UK) in 1861 (10). With the description of a simpler technique of first rib resection in 1966 using an axillary approach (11), surgical relief of this common syndrome became technically easier and more acceptable to the patient and physician (12). In some previous cases of common TOS in our department, the cervical or first rib was resected using the single supraclavicular approach, in order to protect the brachial plexus. However, in the two cases reported in the present study, expansive lesions were observed in the first rib, and if isolated and resected using the single supraclavicular approach a traction of nerves and vessels may occur. Therefore, our group decided to resect the ribs under the assistance of thoracoscopy, and more attention was paid during the supraclavicular incision, in order to protect the nerves and vessels.

There have been only five reports of TOS caused by FD and the optimal management of these lesions is unknown (Table I). In all cases removal of the tumor was associated with amelioration of symptoms.
In conclusion, in cases of TOS caused by FD in the first rib, particularly with expansive growth, the tumors are difficult to resect from supraclavicular or transaxillary approaches. Thoracotomy may lead to greater surgical injury and a longer recovery time. In these cases consideration should be given to a thoracoscopy-assisted supraclavicular approach in order to obtain full vascular/nerve control and a cleaner stripping of the lower edge in the first rib.

\section{References}

1. Pang D and Wessel HB: Thoracic outlet syndrome. Neurosurgery 22: 105-121, 1988.

2. Roos DB: The thoracic outlet syndrome is underrated. Arch Neurol 47: 327-328, 1990.

3. Stanton PE Jr, Vo NM, Haley T, et al: Thoracic outlet syndrome: a comprehensive evaluation. Am Surg 54: 129-133, 1988.

4. Fitzpatrick KA, Taljanovic MS, Speer DP, et al: Imaging findings of fibrous dysplasia with histopathologic and intraoperative correlation. Am J Roentgenol 182: 1389-1398, 2004.

5. Resnick D, Kyriakos M and Greenway GD: Tumors and tumor-like lesions of bone: imaging and pathology of specific lesions. In: Diagnosis of Bone and Joint Disorders. Resnick D (ed). Vol. 4. 4th edition. WB Saunders, Philadelphia, PA, pp3833-3848, 2002.

6. Kricun ME (ed): Tumors of the ribs. In: Imaging of Bone Tumors. 1st edition. WB Saunders, Philadelphia, PA, pp304-328, 1993.

7. Harris WH, Dudley HR Jr and Barry RJ: The natural history of fibrous dysplasia. An orthopaedic, pathological and roentenographic study. J Bone Joint Surg Am 44-A: 207-233, 1962.

8. Jeung MY, Gangi A, Gasser B, et al: Imaging of chest wall disorders. RadioGraphics 19: 617-637, 1999.

9. Melliere D, Ben Yahia NE, Etienne G, et al: Thoracic outlet syndrome caused by tumor of the first rib. J Vasc Surg 14: 235-240, 1991.

10. Coote H: Exostosis of the left transverse process of the seventh cervical vertebra, surrounded by blood vessels and nerves, successful removal. Lancet 1: 360-361, 1861.

11. Roos DB: Transaxillary approach for first rib resection to relieve thoracic outlet syndrome. Ann Surg 163: 354-358, 1966.

12. Roos DB: Experience with first rib resection for thoracic outlet syndrome. Ann Surg 173: 429-442, 1971.

13. Devin R, Branchereau A, Pelissier JF, et al: Thoracic outlet compression syndrome by tumour of the first rib (authors transl). Chirurgie 107: 749-754, 1981 (In French).

14. Karanjia ND and Sayer RE: Thoracic outlet syndrome due to monostotic fibrous dysplasia of the first rib. J R Coll Surg Edinb 35: 111, 1990.

15. Thomas de Montpréville V, Dulmet E, Ponlot R and Dartevelle P: Giant bilateral fibrous dysplasia of first ribs: compression of mediastinum and thoracic outlet. Eur Respir J 8: 1028-1029, 1995.

16. Kemp CD, Rushing GD, Rodic N, et al: Thoracic outlet syndrome caused by fibrous dysplasia of the first rib. Ann Thorac Surg 93: 994-996, 2012. 